\title{
ERRATUM
}

Murat Karabulut · Scott E. Crouter

David R. Bassett Jr

\section{Comparison of two waist-mounted and two ankle-mounted electronic pedometers}

Published online: 20 January 2006

(C) Springer-Verlag 2006

\section{Eur J Appl Physiol (2005): 335-343}

Parts $\mathrm{c}$ and d of Fig. 2 were missing. The complete figure is given below.

The online version of the original article can be found at http:// dx.xoi.org/10.1007/s00421-005-0018-3

M. Karabulut

Department of Health and Exercise Science,

University of Oklahoma, Norman, OK, USA

D. R. Bassett Jr

Department of Exercise, Sport, and Leisure Studies,

The University of Tennessee, 1914 Andy Holt Avenue,

Knoxville, TN 37996, USA

S. E. Crouter $(\square)$

Cornell University, Division of Nutritional Sciences,

279 MVR, Ithaca, NY 14853, USA

E-mail: sec62@cornell.edu

Tel.: + 1-607-2546403

Fax: + 1-607-2548375 

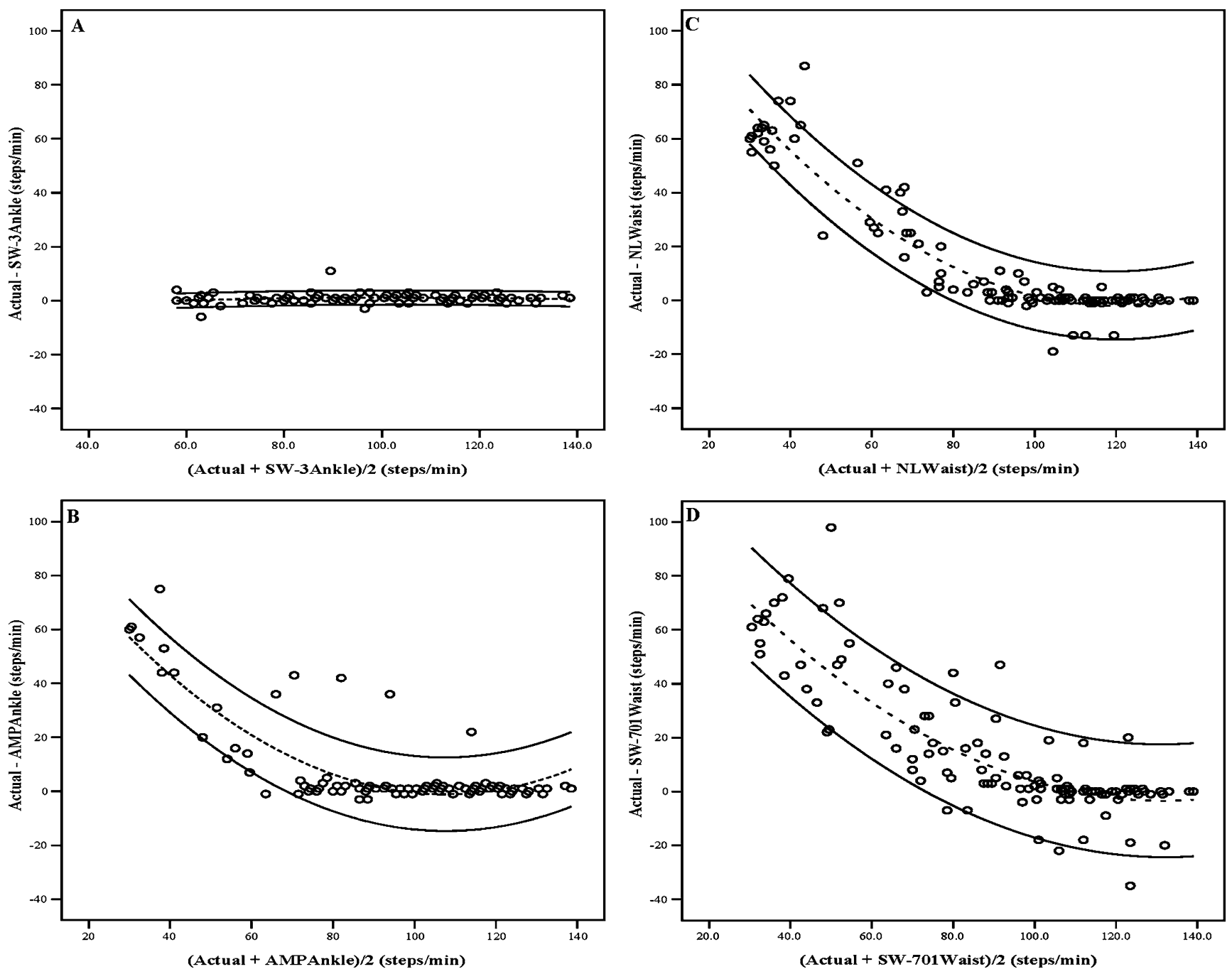

Fig. 2 Modified Bland-Altman plots depicting error scores (actual steps per minute minus pedometer steps per minute) for each pedometer acrossall walking speeds: a Step Watch 3 (SW-3 Ankle),

b AMP-331 (AMP Ankle $_{1}$, c New Lifestyle NL-2000 ( $\left.\mathrm{NL}_{\text {Waist }}\right)$, d Digiwalker SW-701 (SW-701 Waist). Dased lines represent mean difference; solid lines represent $95 \%$ prediction intervals 